\title{
SISTEMAS AGRÍCOLAS TRADICIONAIS: CONHECIMENTOS E INOVAÇÕES SOCIOAMBIENTAIS DOS POVOS E COMUNIDADES TRADICIONAIS FRENTE AOS DESAFIOS CONTEMPORÂNEOS
}

\author{
JOÃO VICTOR MARTINS OLIVEIRA GUERRA ${ }^{1}$ \\ UFRGS, BRASIL
}

\begin{abstract}
RESENHA
EIDT, Jane Simoni; UDRY, Consolacion (editoras técnicas). Sistemas Agrícolas Tradicionais no Brasil. Brasília, DF: Embrapa, 2019.
\end{abstract}

Este livro aborda o modo como distintos povos e comunidades tradicionais plantam seus alimentos ao mesmo tempo em que cultivam seus modos de vida autossustentáveis nas mais diversas paisagens brasileiras. Estas comunidades se destacam pelo seu modo de vida mais autônomo, conquistado através de conhecimentos construídos ao longo de muitos anos de experiência enfrentando adversidades. Adversidades estas que aumentaram ainda mais nas últimas décadas, concomitantemente ao aprendizado de resistir a elas. E foi por essas "boas práticas" que as comunidades foram selecionadas e premiadas ${ }^{2}$, construindo o patrimônio imaterial brasileiro.

Este livro é o terceiro volume da Coleção Povos e Comunidades Tradicionais da Empresa Brasileira de Pesquisa Agropecuária (EMBRAPA). A coleção tem a premissa de valorizar o diálogo de saberes entre os ditos conhecimentos tradicionais e os conhecimentos científicos. Para isso há construção participativa das pesquisas nos contextos dessas comunidades tradicionais, buscando, dessa forma, promover tecnologias, reconhecendo as inovações sociais nos campos da saúde, segurança alimentar, mudanças climáticas, sistemas agrícolas, conservação e uso dos recursos genéticos da biodiversidade, etc., de todos esses povos.

\footnotetext{
${ }^{1}$ Bacharel em ciências sociais (Universidade Federal do Ceará, Brasil). Licenciando em ciências sociais (Universidade Federal do Rio Grande do Sul). E-mail: joaovictormog7@gmail.com

${ }^{2}$ Refere-se ao Prêmio BNDES de Boas Práticas para Sistemas Agrícolas Tradicionais. Este tem o objetivo de reconhecer as boas práticas ligadas à salvaguarda e à conservação dinâmica de bens culturais e imateriais associados à agrobiodiversidade e à sociobiodiversidade presentes nos sistemas agrícolas tradicionais no Brasil. 
Este terceiro volume, especificamente, trata de importantes Sistemas Agrícolas Tradicionais (SATs), que apresentam uma grande agrosociobiodiversidade e contribuem para os desafios da agricultura mundial frente às mudanças climáticas e crises sociais - o que justifica a relevância de tais sistemas enquanto verdadeiros patrimônios imateriais tanto para o Brasil como para o mundo.

Como foi dito, a EMBRAPA foi responsável pela publicação dessa coleção, porém, para o empreendimento deste volume, também houve a colaboração com outras instituições: Banco Nacional do Desenvolvimento Econômico e Social (BNDES), Instituto do Patrimônio Histórico e Artístico Nacional (Iphan) e Organização das Nações Unidas para a Alimentação e a Agricultura (FAO). Estas organizações se reuniram a partir de um importante programa chamado Globally Important Agriculture Heritage Systems (GIAHS), o qual foi incorporado oficialmente em 2015 pela FAO, tendo o objetivo de identificar e salvaguardar os notáveis ecossistemas agrícolas tradicionais ao redor do mundo.

Quando a FAO buscou implementar o GIAHS no Brasil, teve como principal parceiro, primeiramente, o IPHAN, com sua experiência no reconhecimento de patrimônios nacionais. Por sua vez, o IPHAN buscou parceria junto à EMBRAPA com suas pesquisas no campo da agricultura. E, por fim, a implementação desse programa inspirou o BNDES a criar o Prêmio BNDES de Boas Práticas para Sistemas Agrícolas Tradicionais. Sendo os seus ganhadores, relatados neste livro, potenciais integrantes do GIAHS.

Diante disso, o livro foi dividido em duas partes, de forma que abarcassem os resultados de todo esse processo. A primeira parte se divide em três capítulos e tem por objetivo se aprofundar nos SATs mais reconhecidos nacionalmente e internacionalmente. Dessa forma, o primeiro capítulo apresenta o $\mathrm{SAT}^{3}$ do Rio Negro, reproduzido por diversos povos indígenas que habitam as regiões do Médio e Alto Rio Negro, sendo este o primeiro SAT a ser reconhecido como patrimônio imaterial brasileiro pelo IPHAN. Já o segundo capítulo descreve o SAT Quilombola do Vale do Ribeira em São Paulo. Este foi o segundo SAT a ser reconhecido como patrimônio imaterial pelo IPHAN, além de ter também recebido o prêmio do BNDES por suas boas práticas. E, por fim, o terceiro capítulo traz a experiência do SAT da Serra do Espinhaço Meridional em Minas Gerais, os(as) apanhadores(as) de flores sempre-vivas, como se autodefinem. Esta também é uma região com forte presença de remanescentes de quilombos. Eles foram o primeiro SAT brasileiro a ser reconhecido como patrimônio agrícola mundial pelo GIAHS da FAO.

Já a segunda parte está separada em 14 capítulos, sendo que cada um abarca um SAT em específico, completando, assim, os 15 sistemas premiados por suas "boas práticas" pelo BNDES trazidos no livro. São relatos menores que os três primeiros capítulos, mas, ainda assim, relativamente completos. Apesar de cada um dos 14 capítulos serem escritos de diferentes maneiras e contar com distintos autores(as), eles cumprem no geral quatro objetivos: explicar o SAT, descrever o contexto

\footnotetext{
${ }^{3}$ Abreviação para Sistema Agrícola Tradicional.

GUERRA, João Victor Martins Oliveira. Sistemas Agrícolas Tradicionais: conhecimentos e inovações socioambientais dos povos e comunidades tradicionais frente aos desafios contemporâneos. Espaço Ameríndio, Porto Alegre, v. 14, n. 1, p. 355-365, jan./jun. 2020.
} 
das comunidades e povos que habitam a região, detalhar a boa prática premiada em especificamente e finalizar com desafios e perspectivas para a manutenção e reprodução do sistema agrícola.

Essas instituições tão diferentes já indicam esse caráter da obra de ser produzida por diferentes autoras e autores das mais diversas formações. Há engenheiros(as) agrônomos(as), biólogos(as), ecólogos(as), engenheiros(as) florestais, mas também antropólogos (as), sociólogas, pedagogos(as), historiadoras, dentre outras especializações. Entretanto, não são apenas pessoas da academia que escrevem esse livro, mas há também lideranças indígenas, agentes comunitários, elaboradores de políticas públicas, consultores autônomos, além dos(as) autores(as) que fazem parte das próprias instituições que criaram e apoiaram este empreendimento.

$\mathrm{E}$, de fato, para tratar um tema rico e complexo como esse, é imprescindível a cooperação entre as mais diferentes formações. Pois quando se fala de um sistema agrícola tradicional não está só se falando de agricultura, mas de todo o modo de vida e cosmovisão que produzem um sistema agrícola específico. Como é dito ao longo de todo o livro, o sistema agrícola é tido como a base daquela cultura, pois nele abarcamse áreas como educação, saúde, trabalho, fonte de subsistência e renda, entretenimento e festas (muitas ligadas a religião), construção de identidade, criação de laços de solidariedade, etc.

Os povos e comunidades abordados no texto, apesar da classificação "tradicional" em comum, são bastantes distintos, cada qual com uma história particular para contar. Algumas são de povos indígenas, outras quilombolas, enquanto outras são remanescentes tanto de povos quilombolas quanto indígenas, exemplificando as alianças que esses grupos tiveram ao longo da história. Há também comunidades com descendência de imigrantes que formaram comunidades tradicionais, às vezes se associando também a outros povos. Assim, apresentam-se pescadores artesanais, agricultores familiares, quebradeiras de coco, fundo de pasto, faxinais, geraizeiros, vazanteiros, etc, distribuídos em todo o território nacional.

Estes povos e comunidades tratados no livro habitam diferentes regiões brasileiras: Norte, Nordeste, Sul e Sudeste. Nos mais distintos biomas: floresta amazônica, caatinga, mata das araucárias, entre o cerrado e caatinga, entre o cerrado e mata atlântica. Com terras bem distintas: igarapé, serra, sertão, litoral... Com muita chuva e pouca chuva, com as quatro estações ou só com duas...

Todas, porém, têm a especificidade de viver um modo de vida mais autônomo, comparadas com as culturas ditas "modernas" ou "não tradicionais". Estas culturas vêm sendo construídas ao longo de séculos, assim, possuem práticas sustentáveis tanto no modo de lidar com o outro como com o seu meio ambiente, garantindo uma autossuficiência quando têm direito às suas terras.

Desse modo, no livro é citado o Decreto $n^{\circ} 6.040$, de 7 de fevereiro de $2007^{4}$ que reconhece esses povos e comunidades tradicionais e seus

\footnotetext{
${ }^{4}$ Disponível em: http://www.planalto.gov.br/ccivil_03/_Ato2007-2010/2007/Decreto/D6040.htm 
territórios tradicionais, salvaguardando-os através da Política Nacional de Desenvolvimento Sustentável dos Povos e Comunidades Tradicionais. Com isso, temos a definição formal de "povos e comunidades tradicionais" através desse decreto: "grupos culturalmente diferenciados e que se reconhecem como tais, que possuem formas próprias de organização social, que ocupam e usam territórios e recursos naturais como condição para sua reprodução cultural, social, religiosa, ancestral e econômica, utilizando conhecimentos, inovações e práticas gerados e transmitidos pela tradição".

Lendo o texto pode-se perceber a ideia de agroecologia abordada inúmeras vezes. Esta é uma importante chave para compreender as principais problemáticas do texto e das comunidades, pois ela junta duas ideias que na prática são vistas, muitas vezes, como opostas, principalmente pelas sociedades não tradicionais: agricultura e ecologia. Isso é de tal modo tão verdadeiro que os principais empecilhos para a vidas destes povos são produtos dessas ciências: agronomia e ecologia, junto ao Estado ou ao mercado. Sendo que as experiências dessas comunidades trazem grandes contribuições para a reflexão sobre essa dicotomia e para relevantes problemas das nossas vidas contemporâneas.

Uma grande questão atual é o agronegócio, o qual ao mesmo tempo que contribui para a economia brasileira é, também, um grande responsável pelos desastres ambientes: desmatamento e queimadas de florestas, assoreamento de rios, poluição do solo, água e ar, além da alta produção de gases do efeito estufa.

$\mathrm{E}$ por todas essas questões também prejudicam os povos tradicionais. Pois, quando degeneram o ambiente, também criam problemas para os sistemas agrícolas tradicionais. O desmatamento interfere nos períodos de chuva, o corte das matas ciliares causa o assoreamento de rios, riachos e córregos, muitas vezes secando-os e dificultando o abastecimento de água da comunidade. Além dos agrotóxicos que poluem os solos e os lençóis freáticos, prejudicando ainda mais as plantações. Além de tudo isso, buscam constantemente, através da grilagem ou por meio da força, invadir os territórios dessas comunidades.

Por outro lado, muitas vezes para combater essas situações, através dos estudos ecológicos e em parceria com o Estado são criadas áreas de preservação ambiental. Estas buscam impedir o uso humano que destrói aquele meio com desmatamentos, queimadas, etc. Assim, de um lado há essas áreas preservadas com associação entre Estado e ciência ecológica e do outro lado há a ciência agronômica movida pelos interesses mercadológicos do agronegócio.

E entre os dois lados estão os povos e comunidades que lutam pelo direito a seus territórios tradicionais. Não são só as fazendas industriais que avançam sobre suas terras, mas também as áreas de preservação ambiental com suas legislações que impedem a reprodução dos sistemas agrícolas sobre essas áreas. Assim, estes povos ficam no meio do fogo cruzado precisando muitas vezes lutar em duas frentes.

As práticas de tais povos são chamadas de agroecológicas e até agroflorestais, pois eles cultivam diversidade e até florestas em suas 
agriculturas, diferentemente dos monocultivos extensivos do agronegócio.

Diante disso, eles lutam por áreas de preservação ambiental que permitam o uso sustentável dos recursos naturais existentes, pois ao invés de explorar, criam mais recursos e diversidade em colaboração com as outras espécies. Como o livro expõe, as regiões que habitam essas comunidades coincidem com as áreas de natureza mais preservada do entorno. E isso está intrinsecamente ligado ao modo como fazem sua agricultura. Assim, as técnicas desses povos permitem que vivam no mesmo ambiente ao longo de bastante tempo, sempre com recursos disponíveis.

Dessa forma, a agroecologia, como bem representada por eles, é uma agricultura que entende e respeita o ecossistema em que se vive. Cria-se vida de acordo com a singularidade de cada ambiente e entendendo como funciona os diferentes modos de vida naquela região, criando culturas (vegetais, animais e humanas).

Diante disso, estes grupos criam íntimas relações com os seus territórios, construindo suas identidades a partir dos modos que se relacionam em grupo e com a terra. Muitas vezes há uma profunda relação com o alimento que consomem, por exemplo, quando estes fazem parte de narrativas mitológicas que abordam a origem do seu universo, ou quando compõem alguns folclores. Também são realizadas festas, ocorrendo muitas vezes ao longo dos mutirões de plantação, como pode ser visto no quilombo do Vale do Ribeira.

O livro também trata da importância da demarcação das terras para a manutenção de todo um sistema de vida desses povos. Exemplificando porque devem ter o direito às suas terras, pois além de as habitarem há bastante tempo, vivem de uma forma que só é possível manter junto a elas, e ainda contribuem para a sociedade como um todo, com a preservação e criação de biodiversidade.

Com a leitura do livro também se percebe a importância da reforma agrária. Sabe-se que o Brasil é um país com uma das maiores concentrações fundiárias do mundo ${ }^{5}$. Enquanto os povos tradicionais e agricultores familiares lutam pelo direito às suas terras, uma grande quantidade de terra improdutiva concentrada nas mãos de poucos se reproduz ao longo de todo território nacional.

Muito se questiona a necessidade das "grandes" áreas de terra demarcadas para as sociedades indígenas e quilombolas. Este livro contribui para esse debate descrevendo suas técnicas agrícolas chamadas de pousio, coivara, capoeira, roça, etc. Este cultivo exige uma área maior, pois é feito de modo itinerante. Assim, depois de poucos anos cultivando em uma área, muda-se para outra, respeitando o tempo de regeneração da floresta e vegetação daquele lugar. Muitas vezes são mescladas com práticas agroflorestais, em que se cultivam hortas com árvores (geralmente nativas). A partir disso, preservam o ambiente ao mesmo tempo que conseguem sua segurança e soberania alimentar e nutricional.

\footnotetext{
${ }^{5}$ DIEESE (Departamento Intersindical de Estatística e Estudos Socioeconômicos), Estatísticas do Meio Rural 2010-2011. Disponível em: https://www.dieese.org.br/anuario/2011/anuarioRural10-11.html. 
Diante disso, o livro traz a reflexão sobre a importância de se pensar cada vez mais áreas de preservação ambiental com a permissão do uso humano, se este for feito de maneira sustentável e com transparência, como ensinam estes povos e comunidades tradicionais. A obra também expressa uma grande contribuição para os debates atuais sobre como conviver de modo mais sustentável com o meio ambiente ao mesmo tempo em que se produzem meios de existência, combatendo a visão de que as áreas de preservação ambiental e as comunidades indígenas e quilombolas devam ser intocáveis e puras, como museus a céu aberto. Os ambientes podem sim ser manejados de forma sustentável e devem ser, principalmente, para a manutenção das diversas culturas humanas, garantindo segurança alimentar. Portanto, esses povos têm muito o que ensinar e contribuir com as sociedades ditas "modernas".

Os cultivos desses povos estão intimamente ligados também com a saúde ambiental e deles próprios. Ao respeitar o ecossistema não utilizam agrotóxicos e a relação com as "pragas" é feita através do controle biológico, enquanto a adubação é realizada de maneira natural com compostos orgânicos, chamados de bioinsumos. Com isso não causam danos nem ao solo, água e ar, nem à sobrevivência de outras espécies. Isso também garante a produção de alimentos mais saudáveis e nutritivos, gerando a manutenção de corpos mais saudáveis dessas populações.

Além disso, há o cultivo de diversas plantas medicinais, responsáveis pela cura das mais diversas doenças. Assim, tais povos são importantes para a manutenção de saberes milenares sobre as funções de diferentes plantas para o uso na medicina.

Para a manutenção dessa diversidade de espécies de plantas o livro traz exemplos de comunidades que nos últimos anos criaram casas de sementes e viveiros de mudas, fazendo, assim, um banco de germoplasma de muitas sementes crioulas. Com isso, conseguem ter para o futuro inúmeros tipos de um mesmo alimento como milho, mandioca, feijão, etc.

Isso é importante, pois com o avanço do agronegócio é possível que haja contato entre as plantas crioulas e as plantas transgênicas, através da invasão das transgênicas nos cultivos crioulos, com o risco da colonização e proliferação das transgênicas ${ }^{6}$. Os indígenas do sistema agrícola do milho crioulo se preocupam bastante com essa questão, pois, plantas transgênicas, em sua maioria, não produzem sementes. Algo extremamente perigoso que teria como consequência a dependência dessas comunidades por empresas que vendem pacotes de insumos e sementes. Desta forma, com seu banco de reserva de mudas e sementes, conseguem ter uma segurança maior para imprevistos como esses.

Além disso, as mudanças climáticas também criam ambientes diferentes que podem ser mais favoráveis a distintas espécies. Com isso, uma espécie que se adaptaria menos àquele local, pode vir a se adaptar

\footnotetext{
${ }^{6}$ No livro Earth Democracy: Justice, Sustainability, and Peace, de Vandana Shiva, a autora trata de novos valores ambientais para o debate democrático, abordando os temas das lutas no campo da engenharia de alimentos e a privatização de recursos naturais e como resistir a esses ataques. 
melhor com o tempo. Daí a importância de guardar diferentes sementes crioulas de um mesmo tipo de alimento e ir percebendo quais delas se adaptam melhor aos novos tempos.

Outro tipo de imprevisto, causado principalmente pelas mudanças climáticas, é a perda de safras inteiras. Sem a casa de sementes ficaria bastante difícil encontrar sementes para a próxima plantação, gerando a necessidade de ir em busca de recursos fora da comunidade. Todavia, o que ocorre bastante nessas comunidades são as trocas ou doações de sementes entre famílias e grupos, garantindo a autossuficiência da comunidade como um todo.

Em busca de maior autonomia e resistência diante dos desafios apresentados é que esses povos buscam se articular cada vez mais entre si, reinventando suas formas de vida para conseguir continuar com suas culturas e tradições. Diferentemente do modo como são estereotipados por algumas visões, estas comunidades não são estagnadas no tempo. $\mathrm{E}$ pode parecer paradoxal, mas é o dinamismo de sua cultura que permite que ela continue sobrevivendo, ainda mais com as novas problemáticas que se apresentam cotidianamente.

Exemplificando isso, o livro aborda múltiplos problemas que cada povo passou ou ainda passa. Assim cada questão é resolvida de maneira diferente com metodologias particulares de cada conhecimento dos povos. Dessa forma, essas comunidades se articulam criando associações, movimentos, cooperativas, etc.

Como movimentos, buscam lutar por leis que regularizem suas terras, por políticas públicas que respeitem a particularidade de seu modo de vida e contribuam com serviços que ajudem no bem-estar - como na conquista da Lei João Tolentino no sistema agrícola da Comunidade Sobrado.

Também criam associações que entrem em processos judiciais, permitindo a realização de seus sistemas agrícolas em áreas de preservação ambiental. Desse modo, conseguem entrar em um melhor diálogo com os órgãos ambientes, mostrando que suas práticas não são danosas ao meio ambiente.

Com a criação de cooperativas ou associações valorizam seus produtos através da transparência e publicização de seus métodos sustentáveis, que geram um produto orgânico, e se aproveitam do crescente mercado de "produtos verdes" - como ocorreu no sistema de roça de toco em Biguaçu. E os comercializam sejam em grandes mercados ou em feiras orgânicas que organizam.

As comunidades não só se articulam internamente, mas também com instituições e organizações exteriores como universidades, Organizações Não Governamentais (ONG's), organizações internacionais e até órgãos governamentais - como no próprio caso da origem deste livro, originado a partir da busca dessas comunidades para serem reconhecidas como patrimônios imateriais brasileiros, associando-se, assim, a um banco de desenvolvimento social público, a um órgão público, a uma empresa de pesquisa pública e a uma organização internacional. 
Estas articulações funcionam como "armas" na luta por seus direitos e autonomia no seu território. São modos de conseguir (r)existir em seus lugares com condições dignas. Um prêmio como esse se torna um grande capital político em processos judiciais e até na valorização dos produtos que vendem.

A partir disso, é interessante pensar como se deu esse processo de mudanças nessas sociedades através das ideias autonomia, soberania, independência, dependência e interdependência. Uma das maiores características de uma comunidade tradicional é sua autonomia perante o resto das sociedades e seus serviços, ao longo da história, seja através do Estado ou do mercado. Como elas conseguem, no geral, produzir o que comem e, a partir disso, garantir seu modo de subsistência. Ademais, muitas vezes a tradição é passada de maneira oral e pelo trabalho cotidiano, o que seria chamado de "sistema educacional" em uma sociedade dita "não tradicional". Há também seus próprios sistemas de saúde, garantidos por seus rituais chamados de "religiosos" e pelas plantas medicinais que cultivam.

Assim, de forma geral, as comunidades mais perenes, durante séculos, se viram livres da necessidade de contatos maiores com a sociedade "nacional". Isso ocorreu principalmente com as sociedades indígenas e quilombolas, as quais fizeram alianças, ao mesmo tempo que se distanciavam e lutavam contra os colonizadores brancos, que, por sua vez, buscavam escraviza-los e trata-los como recursos, de igual modo que fazem com a "natureza". E é isso que, de modo semelhante, continua ocorrendo até hoje com esses povos, através da renovação do extrativismo ${ }^{7}$, o qual percebe a terra e pessoas como recursos/objetos a serem exploradas de maneira primaria como comodities, assim de maneira violenta destruindo os territórios e com isso a diversidade dos modos de vida.

Podemos perceber como esses povos vivem em interdependência com seu meio. Ou seja, conseguem ser autônomos com soberania alimentar, hídrica e energética quando têm acesso aos seus ambientes de maneira livre. Todavia, quando esse ambiente é danificado ou são impedidos de ter acesso a ele, produz-se uma dependência da relação com as instâncias das sociedades "não tradicionais". Daí, precisam da escola, da moeda padrão, seus trabalhos, seu sistema de saúde, suas estradas, sua aposentadoria, etc. Tornam-se mais dependentes dos serviços exteriores e distantes das suas comunidades, enquanto antes dependiam apenas do ambiente do seu entorno.

Isto pode ser mais bem observado no capítulo do quilombo do Vale do Ribeira. Estes tinham em sua cultura basicamente todos os serviços necessários para superar os desafios cotidianos. Todavia, quando foram impedidos de plantar em suas terras, começaram a ser criadas algumas necessidades. Sem poder plantar, não tinham a segurança alimentar garantida. Foram precisos outros meios para adquirir comida e, com isso,

\footnotetext{
${ }^{7} \mathrm{O}$ livro "As fronteiras do neoextrativismo na América Latina: conflitos socioambientais, giro ecoterritorial e novas dependências" da Maristella Svampa trata desse modelo extrativista exploratório que sempre imperou nas terras colonizadas e como ele se renovou mesmo após o fím das colônias, e, principalmente, como nas últimas décadas surgiram lutas de resistência, gerando conflitos socioambientais. 
foi necessário ir atrás de oportunidades de emprego. Jovens começaram a sair da comunidade, os idosos não podiam mais passar sua tradição oral como faziam na época dos cultivos, além da necessidade da aposentadoria.

Estes são alguns exemplos de como seu modo de vida foi, aos poucos, sendo destruído. Porém, a comunidade não foi passiva diante desses acontecimentos. Assim, criaram-se várias estratégias de resistência a partir de inovações sociais: cooperativa, casa de sementes, feiras, disputas no sistema judicial, etc. Desta maneira, estão reconstruindo seu modo de vida e restabelecendo sua soberania com o apoio de novos aliados.

Consequentemente, essas sociedades tradicionais vão se adaptando às suas novas realidades, ao mesmo tempo em que vão buscando proteger seus territórios. Os atores das sociedades modernas estão, de modo geral, atacando modos de vida tradicionais, assim a alternativa para sua continuidade é buscar aliança com outros atores, além de se reorganizarem para combater os ataques que sofrem.

Nesse sentido, não é possível se pensar o Estado, o mercado ou a ciência no singular e como entidades. A defensoria pública junto aos técnicos agrícolas do Estado, defende os interesses das comunidades quilombolas, ao mesmo tempo em que estes são processados pelos órgãos ambientais estatais. Uma ciência cria os transgênicos, os pesticidas e a maquinaria que avança destruindo seus territórios. Enquanto outra ciência se coloca lado a lado com eles para valorizar seus modos de vida e dialogar construindo projetos - sem contar a própria ciência produzida pelas comunidades. O mercado, representado pelo agronegócio, busca atacá-los. Diante disso, eles criam seus próprios mercados, através de feiras orgânicas, onde cada vez mais vendem o que produzem de excedente. Essas feiras também foram uma forma de diminuir o número de atravessadores. Buscam também se conectar com consumidores conscientes que simpatizam com sua causa, através do crescente mercado de produtos orgânicos. Ao mesmo tempo em que o Estado não regulariza suas terras, cria políticas públicas que auxiliam bastante seus modos de viver - como o Programa de Aquisição de Alimentos (PAA) e o Programa Nacional de Alimentação Escolar (PNAE), ambos utilizados por algumas comunidades trazidas no texto.

Todavia, a história das relações entre os povos indígenas e o Estado é atravessada pela violência e pelo poder tutelar através de políticas e instituições públicas, como é bem tratado por João Pacheco de Oliveira (1988) no seu livro sobre os Ticuna. Diante disso, os povos tradicionais estão e devem estar sempre atentos em relação às políticas, investigando até que ponto estão camuflados como benefícios e por traz busca controlar através da tutela.

João Pacheco de Oliveira (2016) em seu outro livro "O nascimento do Brasil e outros ensaios" trata da história do Brasil de uma maneira bem diferente de como comumente a conhecemos. Primeiramente, por não trazer uma história única e linear, mas com múltiplas linhas de tempo que abarcam as diversas sociedades indígenas de maneira singular. Segundo, porque essas sociedades tradicionais não são colocadas de maneira 
passiva, como geralmente tendem a ser representadas. Na verdade, é mostrado como elas contribuíram de maneira ativa para a construção da sociedade brasileira.

E, de maneira similar, o livro "Sistemas Agrícolas Tradicionais no Brasil" contribui para uma reflexão da história do Brasil e da relação com esses povos tradicionais também dessa maneira diferente, pois tem como objetivo principal mostrar como essas comunidades tradicionais são verdadeiros patrimônios brasileiros, contribuindo de maneira essencial para se refletir sobre a cultura nacional. E para isso, mostram essas sociedades e seus conhecimentos, criando inovações e tecnologias de extrema importância para os desafios contemporâneos nacionais e internacionais. Apresentando, portanto, modos de agricultora que preservam o meio ambiente, e ensinam, por tabela, sobre segurança e soberania alimentar, segurança genética de sementes, conhecimento sobre diferentes cultivos plantas e animais... Enfim, uma grande aula sobre a diversidade e sua capacidade de se adaptar a futuros imprevisíveis. 
Espaço Ameríndio

\section{Referências Bibliográficas}

OLIVEIRA, João Pacheco de. O nascimento do Brasil e outros ensaios: "pacificação", regime tutelar e formação de alteridades. Rio de Janeiro: Contracapa, 2016.

1988.

. “O nosso governo": os Ticuna e o regime tutelar. São Paulo: Marco Zero,

SHIVA, Vandana. Earth Democracy: Justice, Sustainability, and Peace. Cambridge, MA: Southend Press, 2005.

SVAMPA, Maristella. As fronteiras do neoextrativismo na América Latina: conflitos socioambientais, giroecoterritorial e novas dependências. São Paulo: Elefante, 2019.

Recebido em: 21/06/2020 * Aprovado em: 25/06/2020 * Publicado em: 11/09/2020 